\title{
O PERCURSO SENSACIONISTA NA POÉTICA DE ÁLVARO DE CAMPOS: TRÊS MOMENTOS
}

Cristina Alves Locatelli ${ }^{1}$

RESUMO: O presente trabalho busca mostrar como se concretiza o percurso sensacionista na obra poética de Álvaro de Campos. Partindo de pressupostos mais teóricos como o conceito de vanguarda e a influência futurista/simbolista no referido movimento, posteriormente são feitas análises de poemas a fim de se pontuar como o sensacionismo se efetiva não apenas enquanto teoria estética da poesia portuguesa no início do século XX, mas também artística e poeticamente ao longo da obra do poeta em questão.

PALAVRES-CHAVE: sensacionismo; Álvaro de Campos; vanguarda; futurismo; simbolismo.

ABSTRACT: This paper shows how the journey of sensacionismo is made in Alvaro de Campos's poetry. Starting with more theoretical assumptions as the concept of vanguard and the futuristic / symbolist influence in that movement, then analyzes of the poems are made in order to score how the sensacionismo is effective not only as aesthetic theory of Portuguese poetry at the beginning of the twentieth century, but and also artistic and poetically over the work of the poet in question.

KEYWORDS: sensacionismo; Alvaro de Campos; vanguard; futurism; symbolism.

Qualquer que seja a investigação que se faça dos movimentos estético-literários modernistas, esta não pode deixar de apresentar nem que seja uma breve reflexão acerca do conceito de vanguarda adotado. Atentemos para a palavra "reflexão" e não “definição". Tentar "enquadrar" a arte em determinado conceito se trata sem dúvida de um reducionismo que não colabora em nada para a compreensão de suas diversas manifestações, acabando por formatá-las de maneira superficial e simplista. Como então

\footnotetext{
${ }^{1}$ Mestranda em Literatura Portuguesa pela Universidade de São Paulo
} 
se pode pensar em vanguarda e em seus respectivos movimentos tão efervescentes no final do século XIX e início do século XX? Qual era a proposta por eles apresentada? De que maneira se manifestavam? Quais as conseqüências/inovações trazidas por eles? Não. Felizmente não se responderão tais questões e muito menos se fará aqui um tratado sobre a teoria da vanguarda. Bem menos pretensiosamente que isso. Eleger-se-á um determinado movimento literário (o Sensacionismo), de um local específico (Portugal), tendo como foco um de seus poetas mais importantes: Fernando Pessoa, materializado em seu heterônimo Álvaro de Campos. Mas para cada coisa há seu tempo e didaticamente cabe partirmos do que é mais abrangente em busca daquilo que é mais específico.

Tomemos como ponto de partida as palavras de dois autores respectivamente:

Movimento de choque, ao mesmo tempo de ruptura e abertura, a vanguarda, o vanguardismo ou o vanguardista, do mesmo modo que toda a atitude ou situação extrema, não aspirava a qualquer espécie de permanência e muito menos a qualquer imobilidade. Na mesma razão da sua existência levava implícito o espírito de transformação e evolução, prevendo, ambicionando sucessões. (TORRE, 1970, pp. 2122).

[...] as Vanguardas do século XX [...] um conceito operacional que de facto opera; uma acção que de fato age; um programa que se objetiva; uma teoria que, como tal, modifica as práticas. [...] É pois em termos de um projecto dinâmico que hoje se pode falar de Vanguarda, daí decorrendo que qualquer noção de "vanguarda" não pode ser nem absoluta nem estática. (MELO E CASTRO, 1980, p. 17).

O ponto de vista assumido pelos autores é de grande interesse na medida em que aponta como uma das principais características dos movimentos de vanguarda seu caráter dinâmico e mutável. Tendo tal mobilidade "dado o aval" à imensa multiplicidade de idéias e teorias, é ela que vai servir para uma posterior reflexão sobre as possíveis aproximações e/ou distanciamentos entre o sensacionismo e suas influências mais diretas: o simbolismo e o futurismo.

Onde buscar tal princípio de ação, de movimento, de proposta inovadora inerente às vanguardas? Pensemos, pois, nas "ferramentas" utilizadas pelos artistas para defenderem suas propostas e teorias.

Os credos da vanguarda são as suas obras teóricas. Quero dizer que o mais representativo dela são os seus manifestos, as suas efusões egoístas. Daí que a obra de toda vanguarda, no seu momento mais típico, tenha sido essencialmente lírica e teórica. Povoada de versos e 
eriçada de manifestos. Transbordante de desabafos líricos e veemências combativas. (TORRE, 1970, p. 26).

Temos então como objeto de análise do presente estudo, as duas mais relevantes manifestações de uma vanguarda: o sensacionismo enquanto teoria estética (muito bem formalizada nos textos em prosa de Fernando Pessoa) e também a sua veiculação poética (nos versos de Campos), que vão ao encontro às mesmas propostas teóricas (ao menos em um primeiro momento, como veremos.)

O estudo de um movimento de vanguarda implica não apenas na análise da teoria em si, mas também de uma série de outras considerações, ou melhor dizendo, de continuidades e rupturas que a mesma propõe frente ao que é anterior e concomitante a ela. Devido a todo o caráter "renovador/inovador" dos inúmeros "ismos" surgidos no início do século XX, acaba-se muitas vezes por delegar uma importância menor ao que eles apresentam de herança da tradição, desconsiderando-se que:

- a vanguarda em geral não consiste senão numa reformulação ou revitalização de modelos já existentes e aceites, tradicionais ou em vigor no momento;

- a vanguarda pode consistir numa atitude mista de reformulação e negatividade dos modelos disponíveis;

- a vanguarda pode começar pela negatividade completa e acabar na reformulação (e vice-versa?) (HATHERLY, 1979, p. 25).

É o segundo dos pontos citados acima que nos é de maior interesse frente à relação que desejamos evidenciar. Sem adotar uma visão unilateral do conceito de vanguarda, a autora pontua muito bem a linha limítrofe entre inovação/tradição, questões tão presentes na proposta estética modernista. Tendo isso em vista, pode-se agora avançar um pouco na discussão ao analisarmos especificamente a relação e a influência que tanto o futurismo quanto o simbolismo exerceram no sensacionismo de Fernando Pessoa.

O sensacionismo, assim como outras diversas teorias estéticas foi gestado na agitação modernista do início do século XX, especificamente no cenário português da geração de Orpheu. Foi Fernando Pessoa quem lançou suas bases, juntamente com outros movimentos como o paulismo e o interseccionismo. Mas antes de partirmos para a análise do sensacionismo pessoano, ou mais precisamente do percurso que o mesmo opera ao longo da obra de Álvaro de Campos, tratemos de abordar a relação que este possui com o "cenário" poético anterior ao modernismo: o simbolismo. 
A questão da tradição simbolista é uma constante na poesia moderna portuguesa e não poderia ser diferente. Fosse esta entendida como "origem", como ponto de partida dos movimentos literários modernistas ou justamente seu oposto, valores que deveriam então ser renovados e combatidos, é essencial que abordemos tal questão cuidadosamente.

No caso da poética de Fernando Pessoa como um todo, o simbolismo se apresenta muito mais como uma herança do que como "amarra" à vitalidade modernista.

\begin{abstract}
Quando, num dos muitos textos fragmentários que nos deixou [Fernando Pessoa], se refere ao Sensacionismo, que se pode considerar na continuidade do Paulismo e do Interseccionismo, chama a atenção para uma sensibilidade analítica (conseguida pela consciência da sensação ou por uma sua intelectualização) pela qual se assume 'o poder de expressão'. É a este nível, onde se inscreve devidamente o próprio referente da linguagem do poema enquanto linguagem, que a estética do Modernismo e a do Simbolismo encontram um espaço onde se detectam incidências comuns. (GUIMARÃES, 1982, p. 42).
\end{abstract}

Não sendo o simbolismo o único elo de intersecção com o sensacionismo, cabe então abordar a outra proposta bastante influente nesse movimento: o futurismo.

A proposta de se abolir arcaísmos, de se renovar valores, de se exaltar a novidade ia absolutamente ao encontro das transformações que a sociedade sofria nas primeiras décadas do século XX. As inovações nos setores da tecnologia, da ciência, etc. contribuíram muito para que se pensasse um futurismo "latente", que atraía adeptos no campo artístico/estético/literário. O manifesto futurista de Marinetti, datado de 1909 ecoou não apenas na Itália, país de origem, mas também em outros países europeus e no caso de nosso interesse, em Portugal.

“A estética futurista apela sobretudo para a sensação.” (TORRE, 1970, p. 158). Tal citação genérica serve de ponto de partida para se analisar como o conceito de sensação (em comum tanto ao futurismo quanto ao sensacionismo) acaba por se configurar em cada um deles. Para Marinetti, as sensações estavam ligadas mais à percepção subjetiva sendo "tudo conseqüência de uma variação da sensibilidade humana "por acção das grandes descobertas científicas"” e "exaltava pois entusiasta e irreflectidamente a maquinaria, reclamando a absorção do homem pela matéria." (TORRE, 1970, p. 159). 
Isso é muito presente principalmente nas odes do heterônimo engenheiro, mas quando se analisa o conceito de sensação na teoria sensacionista, este se apresenta menos ligado à subjetividade do que à objetividade. Objetividade (intelectualização) esta necessária para que se chegue a uma sensibilidade analítica do mundo (percepção) tendo então como "meta" uma potencialização do poder de expressão criativa.

A importância das sensações não é o único quesito em comum entre o futurismo e o sensacionismo, apesar de se apresentar com perspectivas diferentes em cada um dos movimentos. Outras aproximações podem ser facilmente percebidas, mas deixaremos de evidenciá-las agora a fim de melhor situá-las nos poemas de Álvaro de Campos, que serão abordados a seguir.

Tendo já muito brevemente discutido o conceito de vanguarda e a influência simbolista e futurista no sensacionismo, cabe então analisar como tal movimento se configura como percurso (bastante mutável por sinal) ao longo da obra poética de Campos.

“O sensacionismo não era para Pessoa um sítio em que se pára, mas uma direção em que se aponta" (LOPES, 1971, p. 18) Os poemas escolhidos (sendo que do primeiro será analisado apenas um excerto) corroboram com tal proposta "direcional" e muito mais do que apenas evidenciar um amadurecimento cronológico do poeta, tentar-se-á mesmo apontar como o sensacionismo (inicialmente tão objetivo, intenso, dinâmico, empírico) vai se interiorizando no poeta, alcançando um tom bem mais subjetivo e pessoal.

O poema "A Passagem das Horas", de 1916 é um texto longo, bastante similar às odes e, assim como elas, apresenta bem o sensacionismo enquanto vanguarda modernista, trazendo inovações tanto na estrutura quanto na linguagem empregada ${ }^{2}$. No

\footnotetext{
2 A Passagem Das Horas (excerto)
}

Ave, salve, viva a unidade veloz de tudo!

Ave, salve, viva a igualdade de tudo em seta!

Ave, salve, viva a grande máquina universo!

Ave, que sois o mesmo, árvore, máquinas, leis,

5 Ave, que sois o mesmo, vermes, êmbolos, idéias abstractas,

A mesma seiva vos enche, a mesma seiva vos torna,

A mesma coisa sois, e o resto é por fora e falso,

O resto, o estático resto que fica nos olhos que param,

Mas não nos meus nervos motor de explosão a óleos pesados ou leves,

10 Não nos meus nervos todas as máquinas, todos os sistemas de engrenagem,

Nos meus nervos locomotiva, carro elétrico, automóvel, debulhadora a vapor,

Nos meus nervos máquina marítima, Diesel, semi-Diesel, Campbell,

Nos meus nervos instalação absoluta a vapor, a gás, a óleo e a eletricidade, 
excerto transcrito em nota pode-se perceber o tom de exaltação que inaugura os

Máquina universal movida por correias de todos os momentos!

15 Comboio parte-te de encontro ao resguardo da linha de desvio!

Vapor navega direto ao cais e racha-te contra ele!

Automóvel guiado pela loucura de todo o universo precipita-te

Por todos os precipícios abaixo

E choca-te, trz!, esfrangalha-te no fundo do meu coração!

20 À moi, todos os objectos projécteis!

À moi, todos os objectos direcções!

À moi, todos os objetos invisíveis de velozes!

Batam-me, trespassem-me, ultrapassem-me!

Sou eu que me bato, que me trespasso, que me ultrapasso!

25 A raiva de todos os ímpetos fecha em círculo-mim!

Hela-hoho comboio, automóvel, aeroplano minhas ânsias,

Velocidade entra por todas as ideias dentro,

Choca de encontro a todos os sonhos e parte-os,

Chamusca todos os ideais humanitários e úteis,

30 Atropela todos os sentimentos normais, decentes, concordantes,

Colhe no giro do teu volante vertiginoso e pesado

Os corpos de todas as filosofias, os trapos de todos os poemas

Esfrangalha-os e fica só tu, volante abstracto nos ares,

Senhor supremo da hora europeia metálico e cio.

35 Vamos, que a cavalgada não tenha fim nem em Deus!

Vamos que mesmo eu fique atrás da cavalgada, que eu fique

Arrastado à cauda do cavalo, torcido, rasgado, perdido

Em queda, meu corpo e minha alma atrás da minha ânsia abstracta

Da minha ânsia vertiginosa de ultrapassar o universo,

40 De deixar Deus atrás como um marco miliário nulo,

De deixar o $\mathrm{m}$

Dói-me a imaginação não sei como, mas é ela que dói.

Declina dentro de mim o sol no alto do céu.

Começa a tender a entardecer no azul e nos meus nervos.

45 Vamos ó cavalgada, quem mais me consegues tornar?

Eu que, veloz, voraz, comilão da energia abstracta,

Queria comer, beber, esfolar e arranhar o mundo,

$\mathrm{Eu}$, que só me contentaria com calcar o universo aos pés,

Calcar, calcar, calcar até não sentir...

$50 \mathrm{Eu}$, sinto que ficou fora do que imaginei tudo o que quis,

Que embora eu quisesse tudo, tudo me faltou,

Cavalgada desmantelada por cima de todos os cimos,

Cavalgada desarticulada por baixo de todos os poços,

55 Cavalgada vôo, cavalgada seta, cavalgada pensamento-relâmpago,

Cavalgada eu, cavalgada eu, cavalgada o universo-eu.

Helahoho-o-o-0-0-0-0-0...

Tanto o excerto quanto os poemas na íntegra, presentes ao longo deste trabalho foram transcritos de: PESSOA, F. Poesia completa de Álvaro de Campos. Edição Teresa Rita Lopes - São Paulo: Companhia das Letras, 2007 e tiveram os versos devidamente enumerados a fim de se facilitar a localização dos mesmo ao longo da análise. 
primeiros versos. A intensidade está instaurada pela repetição da palavra "tudo", que se conecta diretamente com a "unidade veloz", a "seta" e a "máquina universo". A rápida sucessão de imagens colabora ainda mais para a intensificação quando o poeta aproxima e coloca ao mesmo nível a natureza ("árvores/vermes"), a tecnologia (“máquina/êmbolos") e idéias ("leis/idéias abstratas") se afirmando ele próprio como estas três "estâncias".

A dinamicidade fica por conta dos versos seguintes, nos quais a "seiva" é a essência que corre tanto no poeta quanto na máquina. Máquina esta que não entra apenas em uma relação comparativa com o corpo daquele que escreve, a questão é mesmo constitutiva ("meus nervos todas as máquinas", "meus nervos locomotiva", “meus nervos máquina marítima”, “meus nervos instalação absoluta a vapor”). Tal característica de se fazer equivaler categorias por meio da simples justaposição de substantivos é extremamente defendida pelo futurismo de Marinetti:

[...] reclamava Marinetti não uma reforma parcial da sintaxe, mas sim a sua destruição absoluta. 'É mister - diz-nos textualmente o seu início - destruir a sintaxe, dispondo os substantivos ao acaso, como se apresentam [...].' Que a cada substantivo se siga sua dupla, ou seja, que se lhe siga, sem qualquer locução conjuntiva, um outro substantivo análogo; [...]” (TORRE, 1970, p. 153).

Nos versos seguintes (15 a 19), nota-se a preferência e a defesa que o poeta faz da intensidade em detrimento da prudência. Esse centra em si mesmo o dinamismo, o movimento dado por "projécteis", “direcções", "velozes”, chegando ao imperativo da gradação ascendente "bato-trespasso-ultrapasso", fazendo com que a velocidade rume do mundo exterior para o interior do próprio poeta ("A raiva de todos os ímpetos fecha em círculo-mim!").

Nos sete versos que se seguem, o que se percebe é ainda a preferência, a defesa que o poeta faz da velocidade, abdicando de tudo aquilo que se configura como subjetividade ("sonhos", "ideais humanitários e úteis", "sentimentos", "filosofia", “poemas"). Tal recusa da subjetividade se alinha muito menos às propostas de Marinetti e muito mais à busca da objetividade defendida por Pessoa em sua teoria do sensacionismo, como já foi apontado anteriormente.

Nos versos 46 e 47 é mais uma vez recorrente o movimento de interiorização do mundo, de internalização do que é abstrato, refletindo e intelectualizando, acabando por objetivar tudo em forma de arte, de linguagem, de versos. O desejo de conter tudo em si mesmo é constante não apenas nesse poema, mas em vários versos do Álvaro de 
Campos sensacionista. Apesar do desejo manifestado, o poeta acaba por assumir seu fracasso frente ao seu desejo ("Que embora eu quisesse tudo, tudo me faltou”) reiterado ainda pelo símbolo, pelo espaço deixado em seguida. Temos então nos versos de Campos o "tema" do poeta falhado, distanciando-se da febre futurista para se aproximar de um questionamento de caráter mais intimista.

A "cavalgada" que era "desmantelada", "desarticulada", "pensamento relâmpago" perde seu caráter repetitivo e ganha o de unidade quando passa à “cavalgada eu”, "cavalgada universo eu” na busca do poeta pela sua interioridade.

Ao longo do poema nota-se que a exaltação de caráter futurista, maquinística, perde um pouco de sua intensidade. Isso pode ser pensado do ponto de vista de TORRE (1970) quando o autor analisa o caráter evasivo do futurismo. Segundo ele, algo de tamanha intensidade não se pode propor como permanente e cabe mesmo que passe, que tome uma determinada direção ${ }^{3}$ (direção esta que no poema é o movimento de interiorização).

Tal constatação dá margem para que se analise o segundo conjunto de versos. Apesar do título muito próximo ao do primeiro texto (exceto pela ausência do artigo definido "a") "Passagem das Horas" de 1923 difere significativamente do primeiro poema interpretado. Nele fica bastante evidente um tom mais reflexivo e uma diminuição de toda aquela intensidade inicial já abordada anteriormente ${ }^{4}$.

\footnotetext{
${ }^{3}$ TORRE, G. de. op. cit (p. 116).

4 Passagem Das Horas

Nada me prende, a nada me ligo, a nada pertenço. Todas as sensações me tomam e nenhuma fica. Sou mais variado que uma multidão de acaso, Sou mais diverso que o universo espontâneo,

5 Todas as épocas me pertencem um momento, Todas as almas um momento tiveram seu lugar em mim. Fluido de intuições, rio de supor - mas, Sempre ondas sucessivas, Sempre o mar - agora desconhecendo-se

10 Sempre separando-se de mim, indefinidamente.

Ó cais onde eu embarque definitivamente para a Verdade, Ó barco, com capitão e marinheiros, visível no símbolo, Ó águas plácidas, como as de um rio que há, no crepúsculo Em que me sonho possível -

15 Onde estais que seja um lugar, quando sois que seja uma hora? Quero partir e encontrar-me Quero voltar a saber de onde, Como quem volta ao lar, como quem torna a ser social, Como quem ainda é amado na aldeia antiga,
} 
O poema, que não é muito extenso, pode ter cada uma de suas três estrofes analisadas de acordo com uma característica específica. Na primeira o caráter é de constatação. A maioria dos versos trata de afirmações que o poeta faz sobre si mesmo e sua (não) relação com o mundo ("Nada me prende, a nada me ligo, a nada pertenço.") devido à característica múltipla de sua personalidade (versos de 2 a 6). Tal multiplicidade é ainda intensificada quando a imagem de "multidão" se torna "de acaso", quando o "universo" se diz "espontâneo", dando ao poeta um reconhecimento da infinitude do seu eu. Considera-se infinito, porém incerto já que é "fluido de intuições", "rio de supor", "ondas sucessivas", fechando a estrofe com a palavra "indefinidamente" que reforça a inexatidão na qual o sujeito se percebe.

Na segunda estrofe, a reflexão presente em todo o poema é ainda intensificada com tom de lamento e de um aparente desejo do poeta encontrar-se ("definitivamente", "Verdade" com a inicial maiúscula), opondo a inconstância do mar, da água agitada da estrofe anterior com as "águas plácidas como as de um rio". A oposição se dá também no verso seguinte entre a palavra "lugar" que é algo fixo e "hora" algo passageiro, fugidio. O desejo de se descobrir, de se reconhecer enquanto sujeito que era apenas aparente é então explicitado pelos versos 16 e 17 e toda uma seqüência de imagens que retoma o que é familiar ("lar", "aldeia antiga", "infância”, "outrora”, "canção de mãe") mostrando um certo ar saudosista, de quem sente falta de um passado estável.

Tendo em vista a última estrofe (depois das constatações da primeira e das reflexões da segunda) o poeta abre mão do desejo de fixar-se usando uma expressão de cunho bem popular ("Merda"). Para ele, a "profissão", os "deveres", a "moral" não

20 Como quem roça pela infância morta em cada pedra de muro,

$E$ vê abertos em frente os eternos campos de outrora

E a saudade como uma canção de mãe a embalar flutua

Na tragédia de já ter passado,

Ó terras ao sul, conterrâneas, locais e vizinhas!

25 Ó linha dos horizontes, parada nos meus olhos,

Que tumulto de vento próximo me é ainda distante,

E como oscilas no que eu vejo, de aqui!

Merda p'rá vida!

Ter profissão pesa aos ombros como um fardo pago,

30 Ter deveres estagna,

Ter moral apaga,

Ter a revolta contra deveres e a revolta contra a moral,

Vive na rua sem siso. 
passam de amarras sociais que devem ser combatidas. O último verso é literalmente imperativo quando afirma "vive" sem juízo, sem pensar, sem refletir.

Se compararmos mesmo que brevemente o primeiro e o segundo poema, pode-se perceber que as "preocupações" do poeta já são outras. Não é mais o mundo exterior, moderno, tecnológico, intenso e veloz que se introjeta nele fazendo-o refletir sobre si mesmo. São agora as reminiscências da infância que trazem um desejo de serenidade, de um auto-reconhecimento, mesmo que tal desejo seja por fim rejeitado pelo poeta. A subjetividade, o questionamento sobre si que é praticamente inexistente no primeiro poema, passa a ser mais relevante neste segundo momento.

Para encerrar então o percurso proposto inicialmente, cabe ainda que se analise um último poema. Este, sem título, datado já de $1935^{5}$.

O poeta inaugura seus versos partindo já de uma identificação pessoal e se evidencia enquanto sujeito já que é um "eu" que se diz "eu mesmo". Porém, tal identificação não se restringe a esse reconhecimento e nos versos seguintes (2 e 3 ) passa a abordar também a relação que o poeta tem com o mundo e como essa exterioridade se introjeta nele.

Seguindo na leitura do poema, nota-se que a relação citada acima é ainda mais explorada quando no verso 5 a palavra "tudo" aparece duas vezes, dando a noção de

Eu, eu mesmo...

$\mathrm{Eu}$, cheio de todos os cansaços

Quantos o mundo pode dar...

Eu...

5 Afinal tudo, porque tudo é eu,

$\mathrm{E}$ até as estrelas, ao que parece,

Me saíram da algibeira para deslumbrar crianças...

Que crianças não sei...

Eu...

10 Imperfeito? Incógnito? Divino?

Não sei.

Eu...

Tive um passado? Sem dúvida...

Tenho um presente? Sem dúvida...

15 Terei um futuro? Sem dúvida,

Ainda que pare de aqui a pouco...

Mas eu, eu...

Eu sou eu,

Eu fico eu,

20 Eu... 
infinitude do poeta, que abarca dentro de si todas as possibilidades (estrelas da algibeira), toda uma grandeza de sensações que lhe for cabível.

De agora em diante, o poema que era até então aparentemente bastante afirmativo, perde tal caráter e passa então a apresentar questionamentos do poeta não apenas sobre si mesmo, mas sobre sua vida como um todo. As três perguntas do verso 10 refletem a dúvida que o poeta agora tem mediante suas (supostas) afirmações, antes tão convictas. A gradação de adjetivos, seguida sempre por interrogações e pelo verso posterior "Não sei.", só tendem a confirmar a incapacidade do poeta em responder as próprias perguntas, fazendo com que ele se contente com o "eu" reticente que encerra a estrofe.

A última estrofe inicia novamente com perguntas, mas estas, diferentemente das anteriores, possuem uma resposta cabal. O "passado", "presente", "futuro" evidenciam o percurso da vida do poeta, que apesar de ter consciência dos acontecimentos de sua existência (repetição de "Sem dúvida..."), ainda assim é um sujeito incompleto, chegando a adotar um ar de desdém, parecendo não se importar que a vida acabe mesmo que em breve (“Ainda que pare de aqui a pouco...")

Quando o poeta tenta por fim compreender-se a si mesmo e afirma "Eu sou eu", parece solucionar a questão. Mas a gradação do verbo "ser" para o verbo "ficar" do verso seguinte mostra ainda a instabilidade do eu do poeta, sua resignação por não conseguir reconhecer-se a si mesmo. A interpretação de "ficar" está ligada a uma questão temporal, um determinado estado de permanência, podendo este ser alterado, autorizando o poeta "ficar" outros “eus" que não aquele, mostrando seu caráter fragmentário enquanto sujeito. O poema se encerra com o mesmo "eu" reticente que permaneceu ao longo de todo o texto, sem que o poeta chegue então a uma resposta ou a uma efetiva identificação de si.

Tendo analisado três poemas de três diferentes momentos da obra de Álvaro de Campos, espera-se que tenha sido possível mostrar como o sensacionismo se operou em cada um deles. Mais do que apenas uma teoria estética proposta por Pessoa, tal movimento efetivamente se fez presente em sua poesia e de alguns de seus contemporâneos como Mário de Sá Carneiro. Fosse dinâmico e exacerbado como no vigor das extensas odes futuristas do heterônimo engenheiro, fosse por um caminho menos intenso e mais reflexivo dos poemas "de meio de obra" ou ainda com todo o caráter subjetivo, introspectivo e por que não um tanto quanto decadente e saudosista 
dos últimos poemas, Campos soube evidenciar a importância das sensações e mais que isso, deixar clara a importância de se pensar e refletir sobre elas, buscando uma outra consciência de mundo e também de si mesmo enquanto sujeito que neste mesmo mundo se insere e atua.

\section{REFERÊNCIAS BIBLIOGRÁFICAS:}

ALCÂNTARA, M. B. R. de. Fernando Pessoa e o Movimento Futurista de Álvaro de Campos, Brasília, Ed. Fundação Waldemar de Alcântara, Thesaurus. 1986.

GUIMARÃES, F. Simbolismo, Modernismo e Vanguardas. Lisboa: Imprensa NacionalCasa Da Moeda, 1982.

Poética do Simbolismo em Portugal. Lisboa: Imprensa Nacional-Casa Da Moeda, 1990.

HATHERLY, A. O Espaço Crítico: do simbolismo à vanguarda. Lisboa: Caminho, 1979.

LOPES, T. R. "Pessoa, Sá-Carneiro e as três dimensões do Sensacionismo" / Teresa Rita Lopes. In: Revista Colóquio/Letras. Ensaio, n. ㅇ 4, Dez. 1971, pp. 18-26.

MELO E CASTRO, E. M. de. (1980), Vanguardas na Poesia Portuguesa do Século XX. Biblioteca Breve, Lisboa, Instituto de Cultura e Língua Portuguesa, 1980.

PESSOA, F. Poesia completa de Álvaro de Campos. Edição Teresa Rita Lopes - São Paulo: Companhia das Letras, 2007.

ROVAI, M. L. Os saberes de si: memória, violência e identidade nos poemas de Álvaro de Campos. 1995 (tese de mestrado em sociologia pela Universidade de São Paulo).

TEIXEIRA, A. L. de F.. Álvaro de Campos, ele mesmo: emergência do sujeito literário na semiperiferia da cena moderna. 2003 (tese de mestrado em sociologia pela Universidade de São Paulo).

TORRE, G. de. História das Literaturas de Vanguarda. Santos: Livraria Martins Fontes, 1970. 